\title{
Delayed recovery from paralysis associated with plasma cholinesterase deficiency
}

\author{
Wenqin Zhou ${ }^{1,2}$ and Sheng LV $\mathrm{V}^{1,2^{*}}$
}

${ }^{*}$ Correspondence:
1602910078@qq.com
${ }^{1}$ Department
of Anesthesiology, West
China Second University
Hospital, Sichuan University,
Chengdu 610041, China
Full list of author information
is available at the end of the
article

article

\begin{abstract}
Introduction: This case was to describe a patient presented a $6 \mathrm{~h}$ length of apnea associated with low cholinesterase activity.

Case description: A 32 years old female patient (body weight $50 \mathrm{~kg}$, height $160 \mathrm{~cm}$ ) was admitted to the hospital for laparoscopy combined with hysteroscopy exploration. The preoperative interrogation revealed no significant personal or family history of adverse reaction to anesthetics. The patient was healthy, with no chronic or systemic disease. ASA classification is I. We performed a general anesthesia with intubation to the patient. Succinylcholine $100 \mathrm{mg}$ was administered in anesthesia induction. After intubation, cisatracurium $3 \mathrm{mg}$ and 3\% sevoflurane were used for anesthesia maintenance. The patient had been mostly unresponsive to external stimuli for 10 min since the end of the operation. Six hours after operation, the patient had totally recovered from paralysis and tracheal tube was extubated. The plasma cholinesterase test showed $291 \mathrm{U} / \mathrm{L}$, significantly below normal (4650-10,440 U/L). Three days after operation, the patient was discharged from hospital with no special discomfort.

Discussion and evaluation: Reduced plasma cholinesterase activity may occur as a result of inherited, acquired defects or iatrogenic causes. If the acquired defects are excluded, low BChE activity is usually considered to be caused by mutations in butyrylcholinesterase gene (BCHE). 80\% of the patients experiencing prolonged neuromuscular blockade following mivacurium have butyrylcholinesteraseen enzyme (BChE) deficiency of genetic origin. The novel mutation of $\mathrm{BChE}$ gene is usually associated with the ethnic of the patients. There is no specific treatment for butyrylcholinesterase deficiency and the mainstream is to maintain ventilatory support until succinlcholine is metabolized out of the myoneural junction and neuromuscular function recovers. Transfusion of fresh frozen plasma is also viable.

Conclusions: Plasma cholinesterase deficiency is a genetic or acquired condition. The most obvious feature of this genetic variants is prolonged recovery from paralysis in which administrated with succinylcholine or mivacurium. Once this is suspected, a laboratory test is important. There is no specific treatment for plasma cholinesterase deficiency. The best and safest way is to let the patient recover spontaneously. Mechanical ventilation support is important.
\end{abstract}




\section{Case report}

Cholinesterase is produced by liver and released into plasma. It is involved in the hydrolysis of ester bonds in muscle relaxants like succinylcholine and several other drugs. It is reported in the case prolonged recovery from paralysis caused by cholinesterase deficiency in a healthy young woman who was not diagnosed so preoperatively.

A 32-year-old female patient (weight $50 \mathrm{~kg}$, height $160 \mathrm{~cm}$ ), ASA I, was admitted to our hospital for laparoscopy combined with hysteroscopy exploration. The preoperative evaluation revealed no significant personal or family history for adverse reaction to anesthetics. Her preoperative tests were normal, including blood routine examination, liver and kidney function, ECG and chest radiograph. A general anesthesia was scheduled for this patient. Midazolam $2 \mathrm{mg}$, fentanyl $0.2 \mathrm{mg}$, propofol $100 \mathrm{mg}$ and succinylcholine $100 \mathrm{mg}$ were administered for anesthesia induction. After intubation, cisatracurium $3 \mathrm{mg}$ and 3\% sevoflurane were used for anesthesia maintenance. The operation finished successfully within $45 \mathrm{~min}$. The vital signs had been stable during the operation.

The patient was mostly unresponsive to external stimuli for $10 \mathrm{~min}$ since the end of the operation. So we gave her neostigmine $(1 \mathrm{mg})$ and atropine $(0.5 \mathrm{mg})$ to reverse the neuromuscular blockade. As our hospital did not have a peripheral nerve stimulator, it was hard to accurately assess the extent of neuromuscular blockade. We had to keep stimulating the patient and observed the reaction. But the patient was still unconscious $30 \mathrm{~min}$ after the operation. The artery blood gas analysis showed slight respiratory acidosis $(\mathrm{pH}$ 7.308, $\mathrm{PCO}_{2}: 48.8 \mathrm{mmHg}, \mathrm{PO}_{2}: 480 \mathrm{mmHg}, \mathrm{BE}-2 \mathrm{mmol} / \mathrm{L}, \mathrm{HCO}_{3}^{-}: 24.6 \mathrm{mmol} / \mathrm{L}, \mathrm{SPO}_{2}$ $100 \%, \mathrm{Na}^{+}: 140 \mathrm{mmol} / \mathrm{L}, \mathrm{K}^{+}: 3.8 \mathrm{mmol} / \mathrm{L}, \mathrm{iCa}^{2+}: 1.13 \mathrm{mmol} / \mathrm{L}$, Hct: $0.34, \mathrm{Hb}: 118 \mathrm{~g} / \mathrm{L}$ ). We suspected the neuromuscular blockade might not be reversed.

One hour and 25 minutes after operation, the patient coughed when endotracheal tube suction. Two hours and fifteen minutes after operation, the tidal volume of the patient still could not reach the standard. Thus, we delivered her into ICU with tracheal tube. Before delivery, the venous blood samples were sent to test plasma cholinesterase level. Six hours after operation, the patient had totally recovered from paralysis and tracheal tube was extubated. The plasma cholinesterase test showed $291 \mathrm{U} / \mathrm{L}$, far below the standard (4650-10,440 U/L). Three days after operation, the patient was discharged home without special discomfort.

\section{Discussion}

When prolonged neuromuscular blockade happens, a systematic review was necessary to perform. First of all, which kind of neuromuscular relaxant was used? Non-depolarizing or depolarizing, the total dosage, the time of use. In this case, we had used succinylcholine as muscle relaxant during induction, followed with cisatracurium $3 \mathrm{mg}$. Succinylcholine is commonly used in the surgical rapid-sequence intubation because of its quick effect and short duration of action (Leadingbam 2007). The onset of muscle relaxant after intravenous injection occurs in about $1 \mathrm{~min}$. After a single intubating dose, a complete recovery normally occurs in about 10-12 min. It is hydrolyzed by plasma cholinesterase (Dell 1996). Reduced plasma cholinesterase activity may occur as a result of inherited, acquired defects or iatrogenic causes (Soliday 2010). Low BChE activity is associated with hepatic and renal diseases. For example, oral contraceptives may decrease the level of $\mathrm{BChE}$, and metoclopramide may lead to low $\mathrm{BChE}$ activity. If 
the acquired defects are excluded, low BChE activity is usually considered to be caused by mutations in butyrylcholineesterase gene (BCHE) (Wichmann et al. 2016). Eight percentage of the patients experiencing prolonged neuromuscular blockade following mivacurium have butyrylcholineesterase enzyme (BChE) deficiency of genetic origin (Ok et al. 2013). BChE deficiency is an autosomal recessive trait. The most important variants are the atypical (A-variants), the Kalow (K-variants), the fluoride (F-variants) and the silent variants. In the White population, the A- and K-variants are the most common. There was little information on genetic variants of $\mathrm{BChE}$ in Chinese population (Lockridge 2015). The novel mutation of BChE gene is usually associated with the ethnic of the patients. In this case, the patient was born in Sichuan, China, Han ethnic group. We also measured the plasma cholinesterase of the patient's sister. It showed that her plasma cholinesterase was significantly below normal. It suggests that the family carries a genetic variant of $\mathrm{BChE}$.

There is no specific treatment for butyrylcholineesterase deficiency and the mainstream is to maintain ventilatory support until succinylcholine is metabolized out of the myoneural junction and neuromuscular function recovers. Transfusion of fresh frozen plasma is also viable.

Once a patient was suspected with plasma cholinesterase deficiency, the following measures could be very important: first of all, mechanical ventilation with sedation is necessary until succinylcholine is completely metabolized; secondly, succinylcholine must be avoided; thirdly, test of plasma cholinesterase level of the patient and his/her family members is need; fourthly, marking the patient as plasma cholinesterase deficiency patient; In the end, reviewing the family history of plasma cholinesterase is important.

The limitation of this case is we did not use the neuromuscular stimulator to measure the neuromuscular blockade because our hospital did not have it. However, it is very important to use a neuromuscular stimulator when muscle relaxant was used. Lack of neuromuscular monitoring may increase the risk of distressing awareness, which may lead to post traumatic stress disorder (PTSD) (Thomsen et al. 2015). The patient should be sufficiently sedated until recovery, if the hospital did not have a neuromuscular stimulator.

\section{Summary}

Plasma cholinesterase deficiency is a genetic or acquired condition.

The most obvious feature of this disease is prolonged recovery from paralysis in which administrated with succinylcholine or mivacurium. Once this disease is suspected, a laboratory test is important. Furthermore, the patient's family should be tested for BChE deficiency. There is no specific treatment for plasma cholinesterase deficiency. The best and safest way is to let the patient recover spontaneously. Mechanical ventilation support with sufficiently sedated is important.

Authors' contributions

WZ: collected the case and drafted the manuscript. SL: edited the manuscript and final approval of manuscript. Both authors read and approved the final manuscript.

Author details

${ }^{1}$ Department of Anesthesiology, West China Second University Hospital, Sichuan University, Chengdu 610041, China. ${ }^{2}$ Key Laboratory of Obstetric Gynecologic and Pediatric Diseases and Birth Defects, Ministry of Education, Chengdu 610041, Sichuan, China. 


\section{Acknowledgements}

This research is supported by Department of Anesthesiology, West China Second Hospital, Sichuan University. The authors thank all the colleagues for their hospitability, time and opinions.

\section{Competing interests}

Both authors declare that they have no competing interests.

\section{Consent to publish}

Consent to publish this case report has been obtained from the participant to report individual patient data.

Received: 26 March 2016 Accepted: 17 October 2016

Published online: 28 October 2016

\section{References}

Dell DD (1996) Plasma cholinesterase deficiency. J Perianesth Nurs 11(5):304-308

Leadingbam CL (2007) A case of pseudocholinesterase deficiency in the PACU. J Perianesth Nurs 22(4):265-274

Lockridge O (2015) Review of human butyrylcholineesterase structure, function, genetic variants, history of use in the clinic, and potential therapeutic uses. Pharmacol Ther 148:34-46

Ok SH, Woo MK, Kim CG, Hwang I, Sohn J-T (2013) Delayed recovery from paralysis by succinylcholine in patient with preoperatively unrecognized and inherited pseudocholinesterase deficiency. Korean Soc Anesth 65(6):19-20

Soliday FK (2010) Pseudocholinesterase deficiency: a comprehensive review of genetic, acquired, and drug influences. J Am Assoc Nurse Anesth 78(4):313-320

Thomsen JL, Nielsen CV, Eskildsen KZ et al (2015) Awareness during emergence from anaesthesia: significance of neuromuscular monitoring in patients with butyrylcholineesterase deficiency. Br J Anaesth (BJA) 115(Suppl. 1):i78-i88

Wichmann S, Færk G, Bundgaard JR, Gätke MR (2016) Patients with prolonged effect of succinylcholine or mivacurium had novel mutations in the butyrylcholineesterase gene. Pharmacogenet Genomics 26(7):351-356

\section{Submit your manuscript to a SpringerOpen ${ }^{\odot}$ journal and benefit from:}

- Convenient online submission

Rigorous peer review

Immediate publication on acceptance

- Open access: articles freely available online

- High visibility within the field

- Retaining the copyright to your article

Submit your next manuscript at springeropen.com 